\title{
Electrospray Ionization Multiple Stage Quadrupole Ion-Trap and Tandem Quadrupole Mass Spectrometric Studies on Phosphatidylglycerol from Arabidopsis Leaves
}

\author{
Fong-Fu Hsu and John Turk \\ Mass Spectrometry Resource, Division of Endocrinology, Diabetes, Metabolism, and Lipid research, \\ Department of Internal Medicine, Washington University School of Medicine, St. Louis, Missouri, USA
}

Todd D. Williams

University of Kansas Mass Spectrometry Laboratory, University of Kansas, Lawrence, Kansas, USA

\author{
Ruth Welti \\ Kansas Lipidomics Research Center, Division of Biology, Kansas State University, Manhattan, Kansas, USA
}

Phosphatidylglycerol (PG) is the major phospholipid of plant chloroplasts. PG from Arabidopsis thaliana has an unusual fatty acyl chain, 3-trans-hexadecenoyl $\left(\Delta^{3} 16: 1\right)$ in the $s n-2$ position of the major 18:3/ $\Delta^{3} 16: 1-\mathrm{PG}$ species, as well as in 18:2/ $\Delta^{3} 16: 1-\mathrm{PG}$ and $16: 0 / \Delta^{3} 16: 1-\mathrm{PG}$. Upon low-energy collisionally activated dissociation (CAD) in a tandem quadrupole or in an ion-trap mass spectrometer, the $[\mathrm{M}-\mathrm{H}]^{-}$ions of the PG molecules containing $\Delta^{3} 16: 1$ give product-ion spectra that are readily distinguishable from those arising from PGs without the $\Delta^{3} 16: 1$ species. The $\Delta^{3}$ 16:1-fatty acyl-containing PGs are characterized by $\mathrm{MS}^{2}$ product-ion mass spectra that contain predominant $[\mathrm{M}-\mathrm{H}-236]^{-}$ions arising from loss of the $\Delta^{3} 16: 1$-fatty acyl substituent as a ketene. This is attributable to the fact that the $\alpha$-hydrogen of the $\Delta^{3} 16: 1$-fatty acid substituent involved in the ketene loss is an allylic hydrogen, which is very labile. This leads to preferential neutral loss of 236 and drastic decline in the neutral loss of 254 (i.e., loss as a fatty acid), the unique features that signify the presence of $\Delta^{3} 16: 1$-fatty acyl containing PGs. The neutral loss scan of 236, thus, provides a sensitive tandem quadrupole mass spectrometric means to identify $\Delta^{3} 16: 1$-containing PG species in lipid mixtures. This low-energy tandem mass spectrometric approach also permits the structures of the Arabidopsis PGs that consist of two isomeric structures to be unveiled. (J Am Soc Mass Spectrom 2007, 18, 783-790) (c) 2007 American Society for Mass Spectrometry

$\mathrm{P}$ hosphatidylglycerol (PG) is the major phospholipid of plant chloroplasts and about $85 \%$ of PG in Arabidopsis thaliana leaves is localized in the chloroplast. PG is thought to play an important role in the ordered assembly and structural maintenance of the photosynthetic apparatus in thylakoid membranes [1-4]. It is required in photosystem II of photosynthesis $[5,6]$. The chloroplast membranes of all photosynthetic eukaryotes contain a high proportion of the unusual fatty 3-trans-hexadecenoic acid [ $\Delta^{3} 16: 1$ or C16:1(3t)], which is always found esterified to the $s n-2$ of glycerol backbone of PG [7-10]. The $\Delta^{3} 16: 1$ acid is the product of the activity of a phosphatidylglycerol fatty

Published online February 14, 2007

Address reprint requests to Dr. Fong-Fu Hsu, Box 8127, Washington University School of Medicine, 660 S. Euclid Ave., St. Louis, MO 63110, USA. E-mail: fhsu@im.wustl.edu acid desaturase, FAD4 (EC 1.14.99.*), which acts exclusively on fatty acyl chains in the $s n-2$ position of PG in plant plastids, probably in the thylakoid membranes [11-14]. Indeed, $\Delta^{3} 16: 1$ is believed to be found only in the photosynthetic membranes of eukaryotes [15].

The biological relevance of 3-trans-hexadecenoic acid in PG has been studied. For examples, loss of $\Delta^{3} 16: 1$ fatty acid in mutants of Chlamydomonas reinharditii resulted in lack of proper assembly of the light-harvesting complexes associated with photosystem II [6, 15]. Removal of $\Delta^{3} 16: 1$ fatty acid from PG by phospholipase-A2 treatment of isolated thylakoids was reported to alter the efficiency of light capture and to change the kinetics of fluorescence induction [16]. In addition, Chapman et al. reported that triazine-resistant plants have a higher level of PG-containing $\Delta^{3} 16: 1$ fatty acid in membrane fractions enriched in photosystem II [17]. Low-temperature 
treatments also induce an increase in the relative content of both linolenic and 3-trans-hexadecenoic acids in thylakoid membrane PG of squash cotyledons [18].

The 3-trans-hexadecenoic acid is atypical because of the trans configuration, and because of the position of the double-bond near the carboxyl (at C3) rather than the methyl end of the fatty acid. The 3-trans-hexadecenoic acid was also found in seaweed [19], in which the structure was established by GC as its fatty acid methyl ester, as well as by GC/MS of the dimethyl-oxazoline derivative $[19,20]$. Although structural studies on PG using tandem quadrupole mass spectrometry have been previously reported [21, 22], plant PG species containing 3-trans-hexadecenoic acid at sn-2 have been identified at the true molecular species level only by a derivatization/HPLC method [23]. ${ }^{\circ}$ Herein, ${ }^{\circ}$ we $^{\circ}$ describe ${ }^{\circ}$ the ${ }^{\circ}$ utilization of tandem quadrupole and multiple-stage quadrupole ion-trap mass spectrometry to discern the fragmentation mechanism underlying the unique pattern of product ion formation by PGs containing $\Delta^{3} 16: 1$. The presence of the $\Delta^{3} 16: 1$-fatty acid at the $s n-2$ position in PG results in a product-ion spectrum readily distinguishable from that obtained from PG that does not contain 3-trans-hexadecenoic acid.

\section{Materials and Methods}

\section{Materials}

Leaves of Arabidopsis thaliana, ecotype Columbia, were placed in 1 volume isopropanol with $0.01 \%$ butylated hydroxytoluene (as an antioxidant) at $75^{\circ} \mathrm{C}(\sim 1$ leaf per $\mathrm{mL}$ isopropanol). After $15 \mathrm{~min}$ in hot isopropanol, 0.5 volumes chloroform and 0.2 volumes water were added. The tubes were agitated for $1 \mathrm{~h}$, followed by removal of the extract. The leaves were re-extracted with 1 volume chloroform:methanol (2:1) with $0.01 \%$ butylated hydroxytoluene five times with appropriately 30 min shaking each time. Solvent was evaporated from the combined extracts, and the residue was dissolved in chloroform. Activated silicic acid (Unisil, Clarkson Chemical Co., Williamsport, PA) was mixed with chloroform and packed into a column. The leaf extract was applied to the column and eluted in five fractions: Fraction I, chloroform:acetone (1:1, vol/vol; 5 column volumes); Fraction II, acetone (10 column volumes); Fraction III, chloroform:methanol (19:1, vol/vol; 10 column volumes); Fraction IV, chloroform:methanol (4:1, vol/vol; 10 column volumes); Fraction V, chloroform: methanol (1:1, vol/vol; 20 column volumes) (modified from $\left.^{\circ}[24]\right) .^{\circ}$ Fraction $^{\circ} \mathrm{V}^{\circ}{ }^{\circ}$ which $^{\circ}$ was $^{\circ}$ enriched $^{\circ}$ in $^{\circ} \mathrm{PG}$, phosphatidylcholine, and phosphatidylinositol, and also containing phosphatidylethanolamine and phosphatidylserine (results not shown), was used in all experiments. PG standards were purchased from Avanti Polar Lipids, Inc. (Alabaster, AL). All other chemicals were purchased from Fisher Scientific (Pittsburgh, PA).

\section{Mass Spectrometry}

Low-energy CAD tandem mass spectrometry experiments were conducted both on a Finnigan (San Jose, CA) LCQ DECA ion-trap (IT) mass spectrometer with the Xcalibur operating system and on a Finnigan TSQ7000 triple-stage quadrupole (TSQ) mass spectrometer with ICIS operating system. Fraction V of the plant lipid extract and methanolic PG standard solution were infused ( $3 \mu \mathrm{L} / \mathrm{min}$ ) to the ESI source, where the skimmer was set at ground potential, the electrospray needle was set at $4.5 \mathrm{kV}$, and temperature of the heated capillary was $260{ }^{\circ} \mathrm{C}$. The automatic gain control of the ion trap was set to $5 \times 10^{7}$, with a maximum injection time of $400 \mathrm{~ms}$. Helium was used as the buffer and collision gas at a pressure of 0.75 mTorr. The $\mathrm{MS}^{\mathrm{n}}$ experiments were carried out with a relative collision energy ranging from 30 to $40 \%$ and with an activation $\mathrm{q}$ value at 0.25 . The activation time was set at $100 \mathrm{~ms}$. Mass spectra were accumulated in the profile mode, typically for 3 to $5 \mathrm{~min}$ for $\mathrm{MS}^{2}$ - and $\mathrm{MS}^{3}$-spectra. The mass resolution of the instrument was tuned to $0.6 \mathrm{Da}$ at half peak height.

For product-ion spectra obtained with a TSQ instrument, the precursor ions were selected in the first quadrupole (Q1), collided with Ar (2.3 mTorr) in the rf-only second quadrupole (Q2), and analyzed in the third quadrupole (Q3). The collision energies were set at $32 \mathrm{eV}$. Both Q1 and Q3 were tuned to unit mass resolution and scanned at a rate of $3 \mathrm{~s} / \mathrm{scan}$. The mass spectra were accumulated in the profile mode, typically for 5 to $10 \mathrm{~min}$ for a tandem mass spectrum.

\section{Results and Discussion}

The ESI full scan mass spectrum of the lipid extract obtained with a TSQ instrument in the negative-ion mode contains several deprotonated $\left([\mathrm{M}-\mathrm{H}]^{-}\right.$) PG species at $m / z 719,721,741,743,745,747$, and 757 (Figure $\left.{ }^{\circ} 1 a\right) .{ }^{\circ}$ The $^{\circ}$ spectrum $^{\circ}$ is ${ }^{\circ}$ identical ${ }^{\circ}$ to $^{\circ}$ that ${ }^{\circ}$ obtained with an IT instrument in the enhanced scan mode $\left(\text { zoom }^{\circ} \text { scan }\right)^{\circ}\left(\right.$ Figure $\left.^{\circ} 1 \mathrm{~b}\right),{ }^{\circ}$ which $^{\circ}$ shows $^{\circ} \mathrm{a}^{\circ}$ low $^{\circ}$ baseline and a well-resolved spectrum. The profile of the tandem mass spectrum obtained by neutral loss scan of 236 (Figure $\left.{ }^{\circ} 1 \mathrm{c}\right)^{\circ}$ is $^{\circ}$ also $^{\circ}$ similar $^{\circ}$ but $^{\circ}$ this $^{\circ}$ scan $^{\circ}$ is $^{\circ}$ selective, ${ }^{\circ}$ as will be discussed below. PG species consisting of two isomeric ${ }^{\circ}$ structures ${ }^{\circ}$ were $^{\circ}$ observed $^{\circ}\left(\right.$ Table $\left.^{\circ} 1\right)$. $^{\circ}$ The $^{\circ}$ structural characterization and the mechanism(s) underlying the fragmentation processes under low-energy CAD are described below.

\section{The Fragmentation Processes Revealed by $M S^{n}$ $(\mathrm{n}=2,3)$ Tandem Mass Spectrometry}

The formation of an ion corresponding to loss of a fatty acid substituent as a ketene (i.e., $\left[\mathrm{M}-\mathrm{H}-\mathrm{R}^{\prime}{ }_{\mathrm{x}} \mathrm{CH}=\mathrm{CO}\right]^{-}$) from a phospholipid is thought to be a charge-driven fragmentation process (CDF) involving participation of the $^{\circ} \alpha$-hydrogen ${ }^{\circ}$ of $^{\circ}$ the $^{\circ}$ fatty $^{\circ}$ acid $^{\circ}$ substituent ${ }^{\circ}[15] .^{\circ}$ The 

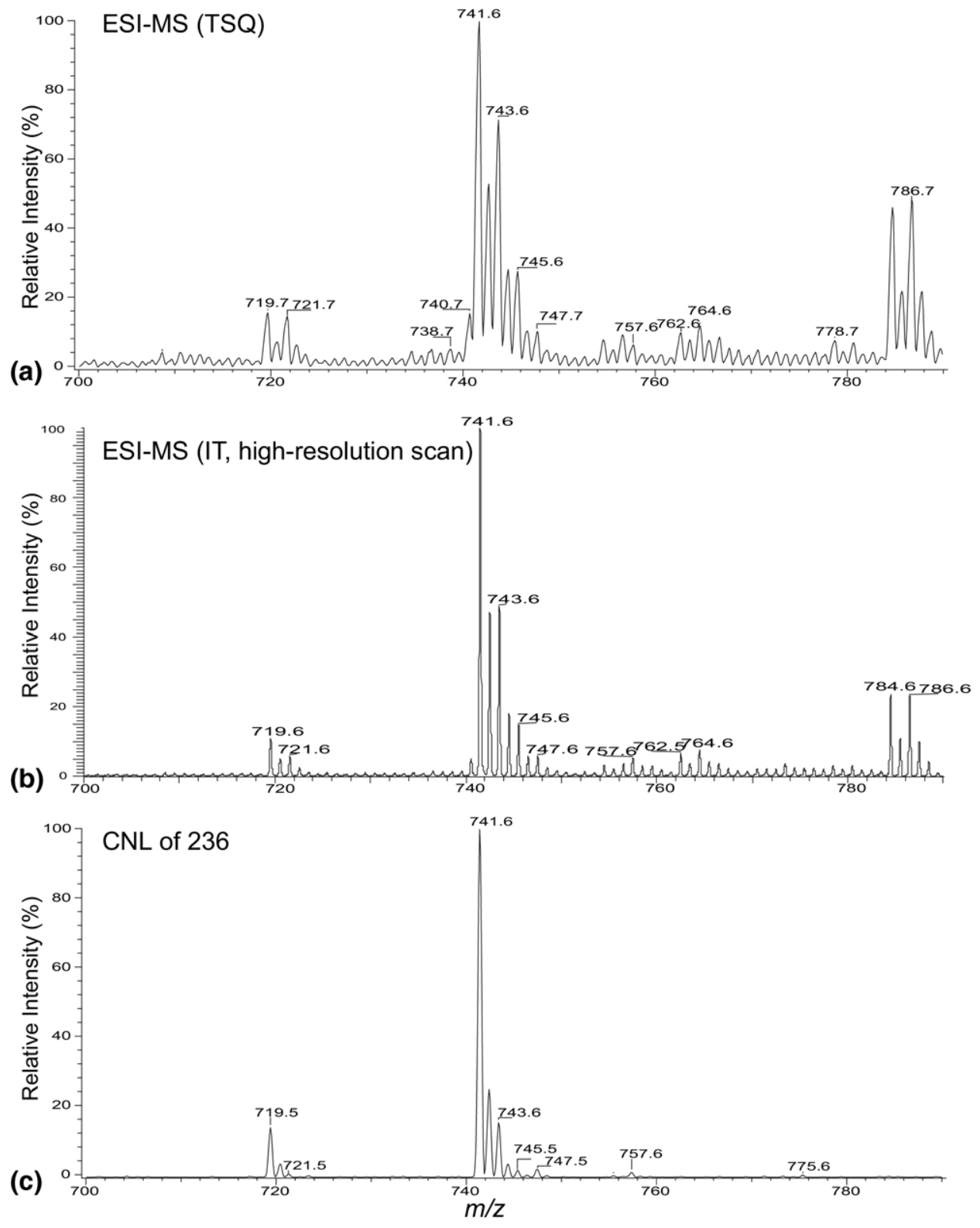

Figure 1. The full scan mass spectra of the lipid extract from plant chloroplasts obtained with (a) a tandem quadrupole, and (b) an IT instrument. Panel (c) shows the tandem mass spectrum of the same mixture acquired by CNL of 236, exhibiting the PG species that contain a 16:1-fatty acid substituent, mainly a $\Delta^{3} 16: 1$-fatty acid substituent at $s n-2$ in the mixture.

anionic charge site at the phosphate abstracts the $\alpha$-hydrogen of the fatty acid substituent, leading to the ketene loss (Scheme 1a). This fragmentation process probably is sterically more favorable with the fatty acid substituent at the $s n-2$ than with that at the $s n-1$ position, resulting in the preferential formation of the ion at $\mathrm{m} / \mathrm{z} 483$ ([M - H $\left.\left.\mathrm{R}_{2}{ }_{2} \mathrm{CH}=\mathrm{CO}\right]^{-}\right)$over the ion at $\mathrm{m} / \mathrm{z} 481([\mathrm{M}-\mathrm{H}-$ $\left.\mathrm{R}^{\prime}{ }_{1} \mathrm{CH}=\mathrm{CO}\right]^{-}$) in the $\mathrm{MS}^{2}$ product-ion spectrum of the $[\mathrm{M}-\mathrm{H}]^{-}$ion of 1-palmitoyl-2-palmitoleoyl-sn-glycero-3phosphoglycerol ${ }^{\circ}\left(16: 0 / \Delta^{9} 16: 1-\mathrm{PG}\right)^{\circ}$ at $^{\circ} \mathrm{m} / \mathrm{z} 7 \mathrm{71}^{\circ}$ (Figure ${ }^{\circ} 2 \mathrm{a}$ ). The phosphate charge site also renders nucleophilic attack more favorable on $\mathrm{C} 2$ than $\mathrm{C} 1$ of the glycerol backbone (Scheme $\mathbf{1 b}$ ), resulting in the $m / z 253$ ion $\left(\mathrm{R}_{2} \mathrm{CO}_{2}^{-}\right)$being more abundant than $m / z 255\left(\mathrm{R}_{1} \mathrm{CO}_{2}^{-}\right)$. These features in the product-ion spectra are readily applicable for determination of the fatty acid substituent identities and their positions ${ }^{\circ}{ }^{\circ}$ the $^{\circ}$ glycerol ${ }^{\circ} b a c k b o n e[22,25]$. The ${ }^{\circ}$ spectrum also contains ions at $m / z 465$ and 463 , arising from losses of the fatty acid substituents as acids. The former ion is more abundant than the latter, consistent with the notion that the fatty acyl species in the $s n-2$ position $\left(\Delta^{9} 16: 1\right)$ is more readily lost.

The product-ion spectrum of the ion at $\mathrm{m} / \mathrm{z} 719$ from the $^{\circ}$ lipid $^{\circ}$ extract $^{\circ}\left(\text { Figure }^{\circ} 2 b\right)^{\circ}$ obtained $^{\circ}$ with $^{\circ}$ the ${ }^{\circ}$ same collision energy using a TSQ instrument is readily distinguishable from that arising from the $16: 0 / \Delta^{9} 16: 1-P G$ 
Table 1. Composition of PG from plant chloroplasts ${ }^{a}$

\begin{tabular}{llc}
\hline$[\mathrm{M}-\mathrm{H}]^{-}$ & \multicolumn{1}{c}{ Structure } & $\begin{array}{c}\text { Relative abundance } \\
\text { (\% of base peak) }\end{array}$ \\
\hline \hline 719.6 & $16: 0 / \Delta^{3} 16: 1-\mathrm{PG}$ & 15 \\
721.6 & $16: 0 / 16: 0-\mathrm{PG}$ & 5 \\
741.6 & $18: 3 / \Delta^{3} 16: 1-\mathrm{PG}$ & 100 \\
743.6 & $18: 2 / \Delta^{3} 16: 1-\mathrm{PG} \&$ & 50 \\
745.6 & $18: 3 / 16: 0-\mathrm{PG}$ & \\
$74: 2 / 16: 0-\mathrm{PG} \&$ & 10 \\
747.6 & $18: 1 / \Delta^{3} 16: 1-\mathrm{PG}$ & 8 \\
757.6 & $18: 1 / 16: 0-\mathrm{PG} \&$ \\
& $18: 0 / \Delta^{3} 16: 1-\mathrm{PG}$ & 6 \\
\hline
\end{tabular}

${ }^{a}$ Data are derived from product-ion analysis with IT and TSO mass spectrometers.

bh denotes hydroxylated.

standard $^{\circ}\left(\right.$ Figure $\left.^{\circ} 2 a\right),{ }^{\circ}$ consistent $^{\circ}$ with ${ }^{\circ}$ the ${ }^{\circ}$ fact $^{\circ}$ that $^{\circ}$ the ion represents a 1-palmitoyl-2-(3-trans)-hexadecenoyl-snglycero-3-phosphoglycerol ${ }^{\circ}\left(16: 0 / \Delta^{3} 16: 1-\mathrm{PG}\right)^{\circ}$ [21]..$^{\circ}$ Both the ions at $m / z 253$ and 255 are less prominent and the ion at $m / z 253$ is less abundant than the ion at $m / z 255$, a reversal in acyl anion abundances compared with those observed for 16:0/ $\Delta^{9} 16: 1-P G$. The ion at $m / z 483$ $\left[\mathrm{M}-\mathrm{H}-\mathrm{R}_{2}^{\prime} \mathrm{CH}=\mathrm{CO}^{-}\right.$, arising from loss of the $\Delta^{3} 16: 1$-fatty acid as a ketene is the most prominent. The dominance of the ion at $m / z 483$ is in accord with the decline of the ion at $m / z 253$, and consistent with the notion that the $\alpha$-hydrogen of the fatty acid substituent participates ${ }^{\circ}$ in $^{\circ}$ the ${ }^{\circ}$ ketene $^{\circ} \operatorname{loss}^{\circ}[22] .{ }^{\circ}$ The $^{\circ} \alpha$-hydrogen ${ }^{\circ}$ of the $\Delta^{3} 16: 1$-fatty acid substituent at $s n-2$ is situated between a carbonyl group and a carbon-carbon doublebond. Thus, it is an allylic hydrogen and is very labile.
Therefore, the fragmentation process leading to loss of the $\Delta^{3} 16: 1$-fatty acyl ketene (Scheme 1a) is the most facile pathway.

The CDF process leading to ketene loss (Scheme 1a) competes with the CDF process that leads to acyl anions by nucleophilic substitution (Scheme 1b). Because loss of the $\Delta^{3} 16: 1$-fatty acid at $s n-2$ as a ketene is the most facile pathway, the process leading to formation of $\mathrm{R}_{2} \mathrm{CO}_{2}^{-}$at $m / z 253$ becomes less favorable. However, the process leading to $\mathrm{m} / \mathrm{z} 481$ due to loss of the 16:0-fatty acid substituent at $s n-1$ as a ketene (Scheme 1a) is less facile than that leading to the $\mathrm{R}_{1} \mathrm{CO}_{2}^{-}$anion at $\mathrm{m} / \mathrm{z} 255$ (Scheme 1b), attributable to the fact that the $\alpha$-hydrogen of the 16:0-fatty acid is less labile. The very facile ketene loss of the $s n-2$ substituent in the PG containing $s n-2$ $\Delta^{3} 16: 1$ leads to a higher ratio of the $\mathrm{R}_{1} \mathrm{CO}_{2}^{-}$ion to the $\mathrm{R}_{2} \mathrm{CO}_{2}^{-}$ion than observed for phospholipids not containing an allylic $\alpha$-hydrogen in the sn-2 fatty acid (Figure ${ }^{\circ} 2 b^{\circ}$ versus ${ }^{\circ} 2 \mathrm{a}$ ).

The $\mathrm{MS}^{2}$ product-ion spectra of $16: 0 / \Delta^{9} 16: 1-\mathrm{PG}$ (Figure $\left.^{\circ} 2 \mathrm{c}\right)^{\circ}$ and $^{\circ} 16: 0 / \Delta^{3} 16: 1-\mathrm{PG}^{\circ}\left(\text { Figure }^{\circ} 2 \mathrm{~d}\right)^{\circ}$ obtained with an IT instrument are similar to those obtained with a TSQ. However, the carboxylate anions at $m / z 253$ and 255 are of low abundance, and the ions at $m / z 463$ and 465 arising from losses of the fatty acid substituents are more abundant, consistent with the notion that the fragmentation processes in an ion-trap are initiated by resonance excitation so that consecutive fragmentations induced by multiple collisions, as seen in an TSQ instrument, are minimal.

The ions at $m / z 465\left(719-\mathrm{R}_{2} \mathrm{CO}_{2} \mathrm{H}\right)$ and $463(719-$ $\mathrm{R}_{1} \mathrm{CO}_{2} \mathrm{H}$ ) gives rise to ions at 391 and 389 , respectively,

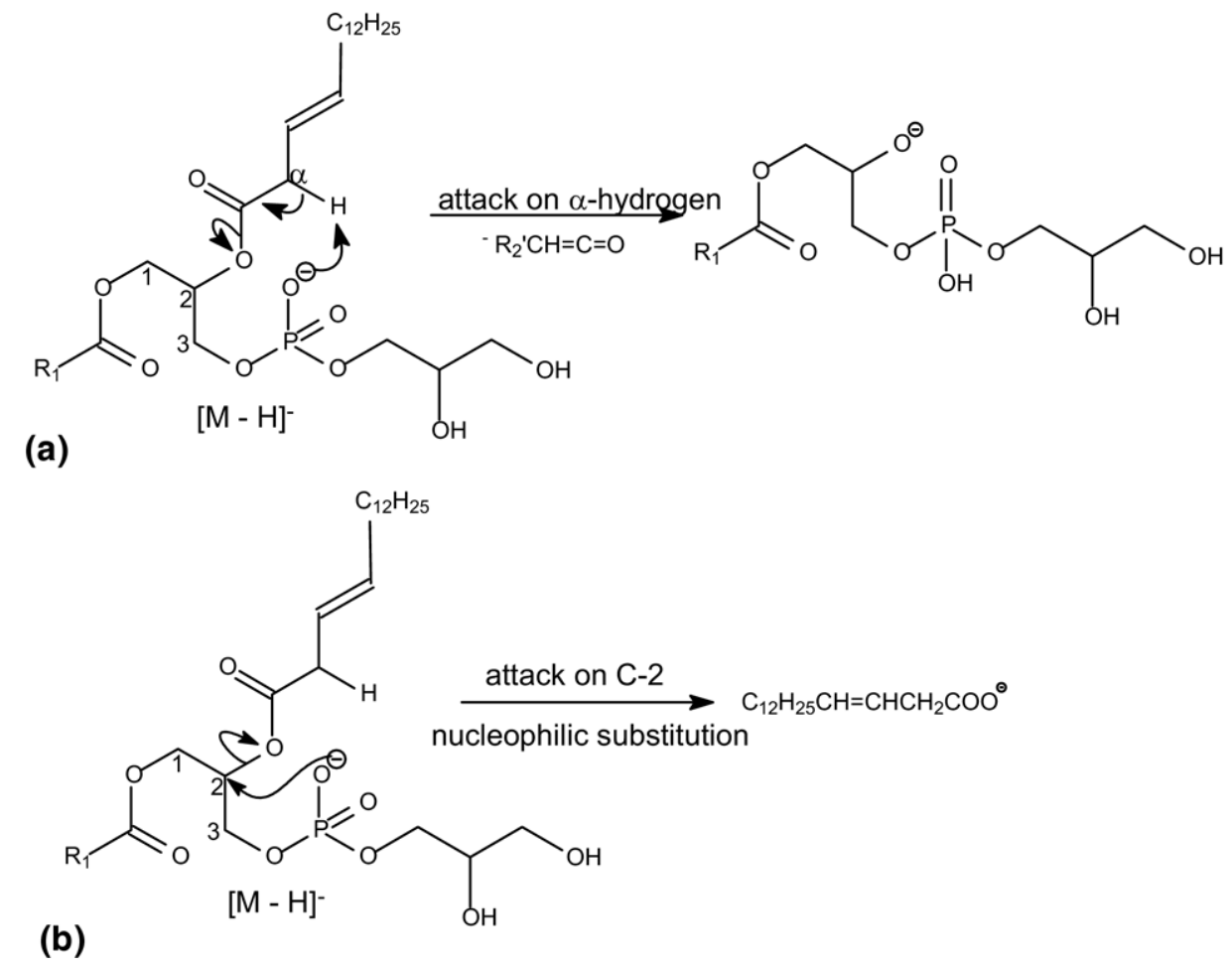

Scheme 1 

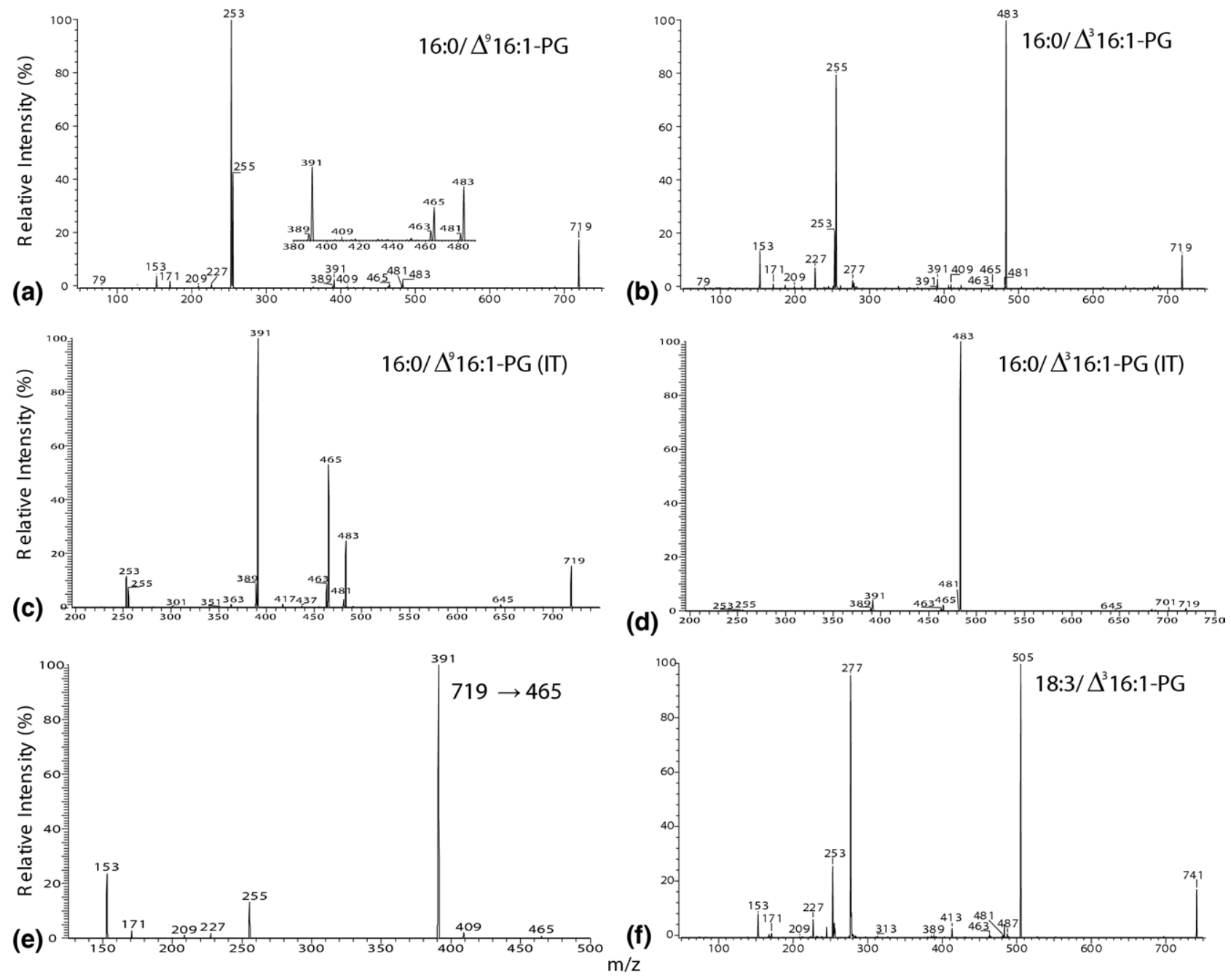

Figure 2. The TSQ product-ion spectra of (a) 16:0/ $\Delta^{9} 16: 1-\mathrm{PG}$, (b) 16:0/ $\Delta^{3} 16: 1-\mathrm{PG}$, and the corresponding IT MS ${ }^{2}$ spectra of (c) 16:0/ $\Delta^{9} 16: 1-\mathrm{PG}$, (d) 16:0/ $\Delta^{3} 16: 1-\mathrm{PG}$. The $\mathrm{MS}^{3}$-spectrum of the ion at $\mathrm{m} / \mathrm{z}$ $465(719 \rightarrow 465)($ e) illustrates that the ions at $m / z 227,171$, and 153 that are characteristic ions of PG and the ion at $\mathrm{m} / \mathrm{z} 391$, which is a precursor ion of the carboxylate anion at $\mathrm{m} / \mathrm{z} 255$ arise from sequential fragmentation of $m / z 465$. Panel (f) is the product-ion spectrum of the ion at $\mathrm{m} / \mathrm{z} 741$, which is similar to the spectrum shown in (b), suggesting the presence of $18: 3 / \Delta^{3} 16: 1-\mathrm{PG}$, the major species found in the PG extract.

by loss of a $\mathrm{C}_{3} \mathrm{H}_{6} \mathrm{O}_{2}$ residue. The fragmentation processes are supported by the IT $\mathrm{MS}^{3}$-spectra of the $\mathrm{m} / \mathrm{z}$ $465^{\circ}\left(719^{\circ} \rightarrow{ }^{\circ} 465\right)^{\circ}\left(\right.$ Figure $^{\circ} 2 \mathrm{e}^{\circ}$ and $^{\circ} 463^{\circ}\left(719^{\circ} \rightarrow^{\circ} 463\right)^{\circ}$ ions (not shown), which are dominated by the ions at $\mathrm{m} / \mathrm{z}$ 391 (Figure 2e) and 389 , 'respectively. The ${ }^{\circ}$ ions at $\mathrm{m} / \mathrm{z} 391$ $(483$ - 92) and $389(481$ - 92) can also arise from $m / z 483$ and 481, respectively, by elimination of a glycerol residue. However, these fragmentation pathways are less favorable, as revealed by the IT $\mathrm{MS}^{3}$-spectra of $\mathrm{m} / \mathrm{z}$ $483(719 \rightarrow 483)$ (not shown). The ions at $m / z 391$ and 389 also give rise to the ions at $m / z 255$ and 253, respectively, ${ }^{\circ}$ by $^{\circ}$ neutra ${ }^{\circ} \operatorname{loss}^{\circ}$ of $^{\circ} 136^{\circ}\left[22,{ }^{\circ} 25,{ }^{\circ} 26\right] .^{\circ}$ These data suggest that, in the TSQ product-ion spectra, the carboxylate anions at $m / z 255$ and 253 of $16: 0 / \Delta^{9} 16: 1-P G$ (Figure $\left.^{\circ} 2 \mathrm{a}\right)^{\circ}$ and $^{\circ} 16: 0 / \Delta^{3} 16: 1-\mathrm{PG}^{\circ}\left(\text { Figure }^{\circ} 2 \mathrm{~b}\right)^{\circ}$ can $^{\circ}$ arise from consecutive fragmentations in addition to the nucleophilic substitution pathway shown in Scheme $\mathbf{1 b}$.
This is consistent with the low abundance of the carboxylate anions and the higher abundance of the ions at $m / z 465 / 463$ and $391 / 389$ in the IT MS $^{2}$ product-ion spectra $^{\circ}\left(\right.$ Figure $^{\circ} 2 \mathrm{c}^{\circ}$ and $\left.^{\circ} \mathrm{d}\right)$.

The $^{\circ}$ ion $^{\circ}$ at $^{\circ} \mathrm{m} / \mathrm{z} 741^{\circ}$ (Figure $\left.^{\circ} 1\right)^{\circ}$ undergoes $^{\circ}$ fragmentation processes similar to $16: 0 / \Delta^{3} 16: 1-\mathrm{PG}$ and gives rise to a product-ion spectrum similar to that shown in Figure $2 \mathrm{~b}$. The ${ }^{\circ}$ spectrum $^{\circ}$ (Figure $2 \mathrm{f}$ ) is $^{\circ}$ dominated by the ion at $m / z 505(741-236)$ corresponding to loss of a 16:1-fatty acid substituent as a ketene and analogous to the ${ }^{\circ} \mathrm{m} / \mathrm{z} 483^{\circ}$ ion $^{\circ}$ in $^{\circ}$ Figure $^{\circ} 2 \mathrm{~b} .^{\circ}$ The $^{\circ}$ profile $^{\circ}$ of ${ }^{\circ}$ the $^{\circ} \mathrm{MS}^{2}-$ spectrum obtained with an IT instrument (data not shown) is ${ }^{\circ}$ similar'to that ${ }^{\circ}$ hown in Figure $2 d$. The ${ }^{9}$ results indicate that the compound consists of a $\Delta^{3} 16: 1$-fatty acid substituent, most likely at $s n-2$. The ions at $m / z 481$, arising from loss of 18:3-fatty acid as a ketene and at $\mathrm{m} / \mathrm{z}$ 277 , corresponding to an 18:3-fatty acid anion, are also 
present in the spectrum, suggesting that an 18:3 fatty acid substituent resides at $s n-1$. The spectrum also contains ions at $\mathrm{m} / \mathrm{z} 227,209,171$, and 153 , ions commonly ${ }^{\circ}$ observed ${ }^{\circ}$ for $^{\circ} \mathrm{PG}^{\circ}[15],{ }^{\circ}$ confirming ${ }^{\circ}$ that ${ }^{\circ}$ the ${ }^{\circ}$ ion represents 18:3/ $\Delta^{3} 16: 1-\mathrm{PG}$.

\section{Characterization of PG Consisting of Isomeric Structures}

Product-ion analysis revealed two isomeric structures for $^{\circ}$ the ${ }^{\circ}$ ions ${ }^{\circ}{ }^{\circ}{ }^{\circ} \mathrm{m} / \mathrm{z} 743,{ }^{\circ} 745^{\circ}{ }^{\circ}$ and ${ }^{\circ} 747^{\circ}$ (Table ${ }^{\circ} 1$ ). ${ }^{\circ}$ Determination of the structures is exemplified by the ion at $\mathrm{m} / \mathrm{z}$ 743. The $\mathrm{MS}^{2}$ product-ion spectrum obtained with a TSQ $^{\circ}$ instrument ${ }^{\circ}\left(\right.$ Figure $\left.^{\circ} 3 a\right) .{ }^{\circ}$ contains $^{\circ}$ ions $^{\circ}{ }^{\circ}{ }^{\circ} \mathrm{m} / z$ 227, 209, 171, and 153 that are diagnostic ions for PG, along with two pairs of the carboxylate anions at $\mathrm{m} / \mathrm{z} 255 / 277$ and $279 / 253$, indicating that the ion may consist of 18:3/16:0-PG and 18:2/16:1-PG isomers. The 18:3/16: 0 -PG structure is recognized by the observation of the ions at $m / z 505$ and 487, arising from loss of a 16:0-fatty acid substituent as a ketene and as an acid, respectively, and the ions at $\mathrm{m} / \mathrm{z} 483$ and 465, arising from the analogous losses of an 18:3-fatty acid substituent. The ion at $\mathrm{m} / \mathrm{z} 505$ is more abundant than $\mathrm{m} / \mathrm{z} 483$, and the ion at $\mathrm{m} / \mathrm{z} 487$ is also more abundant than the ion at $\mathrm{m} / \mathrm{z} 465$, indicating that the 16:0- and 18:3-fatty acid substituents are located at $s n-2$ and $s n-1$, respectively, consistent with the observation of a greater abundance of the ion at $\mathrm{m} / \mathrm{z} 255$ than the ion at $\mathrm{m} / \mathrm{z} 277$. The structural assignment is further supported by the $\mathrm{MS}^{2}$ product-ion spectrum obtained with an IT MS (Figure ${ }^{\circ} 3 b$ ), ${ }^{\circ}$ in $^{\circ}$ which $^{\circ}$ the $^{\circ}$ differential $^{\circ}$ formation ${ }^{\circ}$ of ${ }^{\circ}$ the above fragment ions also can be seen. The spectrum also features the greater prominence of the ion at $\mathrm{m} / \mathrm{z}$ 413 (487 - 74), arising from loss of $\mathrm{C}_{3} \mathrm{H}_{6} \mathrm{O}_{2}$ from $\mathrm{m} / z$ 487, as compared with the ion at $\mathrm{m} / \mathrm{z} 391$ (465-74), arising from further loss of $\mathrm{C}_{3} \mathrm{H}_{6} \mathrm{O}_{2}$ from $\mathrm{m} / z 465$.

The assignment of the $18: 2 / \Delta^{3} 16: 1-\mathrm{PG}$ structure is supported by the $^{\circ}$ presence ${ }^{\circ}$ f the $^{\circ}$ ion ${ }^{\circ}{ }^{\circ} \mathrm{m} / \mathrm{z} 507^{\circ}$ (Figure 3 a and $b)$, corresponding to loss of the 16:1-fatty acid substituent as a ketene. This ion is most prominent in the product-ion spectrum obtained with an ion trap (Figure ${ }^{\circ} \mathrm{b}$ ), ${ }^{\circ}$ but $^{\circ}$ the $^{\circ}$ ion ${ }^{\circ} \mathrm{at}^{\circ} \mathrm{m} / \mathrm{z} 489$, ${ }^{\circ}$ arising ${ }^{\circ}$ from ${ }^{\circ}$ loss $^{\circ}$ of the 16:1-fatty acid substituent as an acid, is of low abundance, suggesting that the 16:1-fatty acid substituent is 3-trans-hexadecenoic acid, the unusual fatty acid attached to the $s n-2$ position of PG found in plant chloroplasts. The assignment of the $18: 2 / \Delta^{3} 16: 1-\mathrm{PG}$
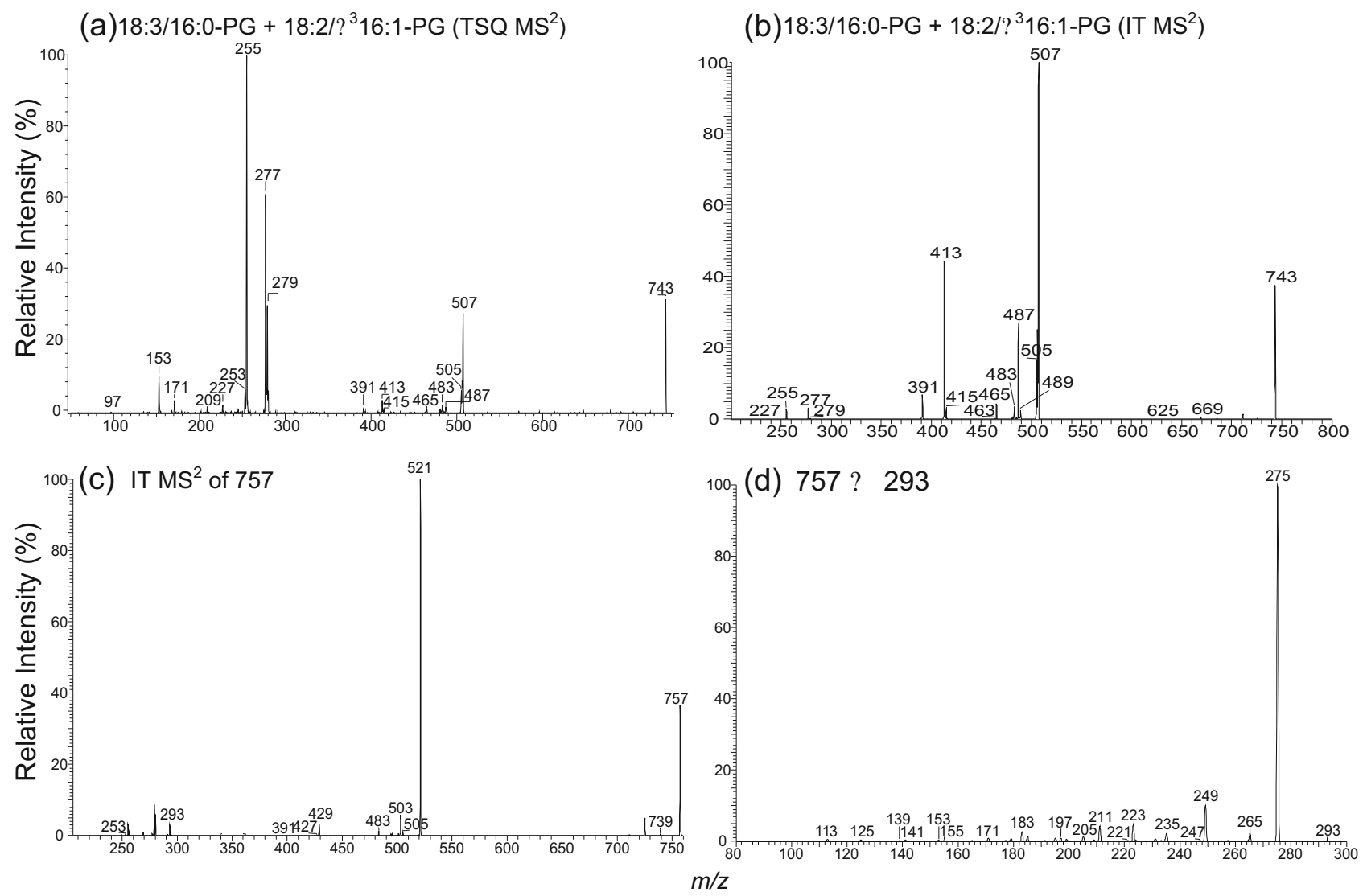

Figure 3. The product-ion spectrum of the ion at $m / z 743$ obtained with (a) a TSQ, and (b) an IT instrument. Panel (c) is the IT $\mathrm{MS}^{2}$-spectrum of the ion at $\mathrm{m} / \mathrm{z} 757$, which may consist of a h18:3/ $\Delta^{3} 16: 1-P G$ structure. The presence of the hydroxylated 18:3-fatty acid substituent is consistent with the presence of a prominent ion at $\mathrm{m} / \mathrm{z} 275$, corresponding to loss of $\mathrm{H}_{2} \mathrm{O}$ from $\mathrm{m} / \mathrm{z} 293$, as shown in the MS ${ }^{3}$-spectrum of $m / z 293(757 \rightarrow 293)(d)$. 
structure is also consistent with the observation of a higher abundance of the ion at $m / z 279$ than the ion at $\mathrm{m} / \mathrm{z} 253^{\circ}$ (Figure $\left.{ }^{\circ} 3 \mathrm{a}\right){ }^{\circ}{ }^{\circ}$ similar $^{\circ}$ to $^{\circ}$ the $^{\circ}$ profile $^{\circ}$ seen $^{\circ}$ for ${ }^{\circ}$ the 16:0/ $\Delta^{3} 16: 1-\mathrm{PG}^{\circ}$ (Figure $\left.2 \mathrm{~b}\right)^{\circ}$ and ${ }^{\circ} 18: 3 / \Delta^{3} 16: 1-\mathrm{PG}^{\circ}$ (Figure 2f), ${ }^{\circ}$ which ${ }^{\circ}$ contain $^{\circ}$ the ${ }^{\circ} \Delta^{3} 16: 1-$ fatty $^{\circ}$ acid $^{\circ}$ substituent $^{\circ}$ at $s n-2$.

\section{Identification of PG Species Containing $\Delta^{3}$ 16:1-Fatty Acid Substituent Via Constant Neutral Loss (CNL) Scanning}

As seen earlier, the product-ion spectra of PG containing the $\Delta^{3} 16: 1$-fatty acid substituent at $s n-2$ are dominated by the $[\mathrm{M}-\mathrm{H}-236]^{-}$ion, arising from neutral loss of the $\Delta^{3} 16: 1$-fatty acyl substituent as a ketene, and the $[\mathrm{M}-\mathrm{H}-254]^{-}$ion, arising from neutral loss of the $\Delta^{3} 16: 1$-fatty acyl substituent as an acid, is of low abundance. ${ }^{\circ} \mathrm{As}^{\circ}$ shown $^{\circ}$ in $^{\circ}$ Figure $^{\circ} 1 c^{\circ}$, the $^{\circ}$ spectrum ${ }^{\circ}$ acquired from CNL scanning of 236 of the lipid extract is similar to ${ }^{\circ}$ the $^{\circ}$ full $^{\circ}$ scan $^{\circ}\left(\right.$ Figure $^{\circ} 1 \mathrm{a}^{\circ}$ and $^{\circ} \mathrm{b}$ ), ${ }^{\circ}$ but ${ }^{\circ}$ only ${ }^{\circ}$ peaks ${ }^{\circ}$ from PGs that consist of $\Delta^{3} 16: 1$-fatty acid are observed. The spectrum clearly demonstrates that the PG species from plant chloroplasts mainly contain a $\Delta^{3} 16: 1$-fatty acid substituent, consistent with the results from the structural analysis of the individual ions from product-ion spectra $^{\circ}\left(\right.$ Table $\left.^{\circ} 1\right) .{ }^{\circ}$ In $^{\circ}$ contrast, $^{\circ}$ the ${ }^{\circ}$ signals ${ }^{\circ}$ of ${ }^{\circ}$ the ${ }^{\circ}$ similar ions in the spectrum acquired from CNL scanning of 254 (see Supplementary Material section, which can be found in the electronic version of this article) are weak, and the intensity of the ion at $m / z 741$, for example, is $<2 \%{ }^{\circ}$ than $^{\circ}$ that $^{\circ}$ seen ${ }^{\circ}{ }^{\circ}{ }^{\circ}$ Figure $^{\circ} 1 c^{\circ}$. This ${ }^{\circ}$ drastic $^{\circ}$ change ${ }^{\circ}$ in the relative sensitivity between the spectra obtained from CNL scannings of 236 and of 254 provides distinction of the $\Delta^{3} 16: 1$-fatty acid bearing PG from, for example, $\Delta^{9} 16$ :1-bearing PGs, which also undergo similar neutral losses (i.e., CNL of 254 and 236), but in a different manner. Therefore, tandem quadrupole mass spectrometry with CNL scanning of 236, in combination with CNL scanning of 254 that confirms that the species indeed contains $\Delta^{3} 16: 1$-fatty acid, provides a useful means for sensitive detection of PG species containing a $\Delta^{3} 16: 1$-fatty acid substituent in mixtures.

In $^{\circ}$ Figure $^{\circ} 1 c^{\circ}{ }^{\circ}$ an $^{\circ}$ ion $^{\circ}$ at $^{\circ} \mathrm{m} / \mathrm{z} 757^{\circ}$ is $^{\circ}$ also $^{\circ}$ present, suggesting that the ion may arise from a PG containing a $\Delta^{3} 16: 1$-fatty acid substituent, probably a hydroxylated 18:3/ $\Delta^{3} 16: 1-P G$. This structural assignment is based on the finding that the profile of the IT $\mathrm{MS}^{2}$-spectrum of

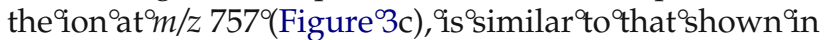
Figure $2 d$, supporting the presence of ${ }^{\circ}{ }^{\circ} \Delta^{3} 16$ :1-fatty acid substituent. The ion at $\mathrm{m} / \mathrm{z} 293$ may represent a hydroxylated 18:3-fatty acid (h18:3) substituent. This speculation is based on the notion that the ion at $m / z 275$ ( $293-\mathrm{H}_{2} \mathrm{O}$ ), arising from loss of $\mathrm{H}_{2} \mathrm{O}$ is the predominant ion in the IT $\mathrm{MS}^{3}$-spectrum of $293(757 \rightarrow 293)$

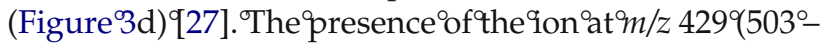
74 ), arising from $m / z 503$ by loss $\mathrm{C}_{3} \mathrm{H}_{6} \mathrm{O}_{2}$ and the presence of the ion at $\mathrm{m} / \mathrm{z} 739$, arising from a water loss from $^{\circ} 757^{\circ}\left(\text { Figure }^{\circ} 3 \mathrm{c}\right)^{\circ}$ are $^{\circ}$ also $^{\circ}$ consisten $^{\circ}$ with $^{\circ}$ the ${ }^{\circ}$ pres- ence of a hydroxylated 18:3-fatty acid residue in the molecule. However, further study is necessary to support the assigned structure and to confirm that the compound is indeed in the PG mixture.

\section{Conclusions}

The fragmentation processes observed for the PG species bearing a $\Delta^{3} 16: 1$-fatty acid at $s n-2$ are consistent with the mechanisms ${ }^{\circ}$ previously proposed by us $\left.922,25,26\right]$. These PG species are readily distinguishable from other species in this phospholipid class by their unique low-energy tandem mass spectra from the $[\mathrm{M}-\mathrm{H}]^{-}$ion, in which the fragment ion reflecting loss of the $\Delta^{3} 16: 1$-fatty acid as a ketene (i.e., the $[\mathrm{M}-\mathrm{H}-236]^{-}$) is prominent due to the labile nature of the $\alpha$-hydrogen of $\Delta^{3} 16: 1$-fatty acid substituent. ${ }^{\circ}$ Recently, ${ }^{\circ}$ Moe $^{\circ}$ et $^{\circ}$ al. ${ }^{\circ}[28]^{\circ}$ and ${ }^{\circ}$ Thomas $^{\circ}$ et $^{\circ} a 1$. [29] ${ }^{\circ}$ described $^{\circ} \mathrm{ESI}^{\circ}$ tandem ${ }^{\circ}$ mass ${ }^{\circ}$ spectrometric ${ }^{\circ}$ methods for location of the olefinic sites of phospholipids, following conversion to their 1,2-dihydroxy derivatives by $\mathrm{OsO}_{4^{\circ}}[28]^{\circ}$ or $^{\circ}$ on-line ${ }^{\circ}$ ozonolysis ${ }^{\circ}$ of ${ }^{\circ}$ double $^{\circ}$ bonds ${ }^{\circ}$ to yield both a terminal oxoalkanoyl and a terminal Chydroperoxy, C-methoxy alkanoyl radyl containing phospholipid $^{\circ}$ anions $^{\circ}$ [29]. ${ }^{\circ}$ These $^{\circ}$ approaches $^{\circ}$ are straightforward and should be useful, in particular, for locating the double-bond(s) of the fatty acid substituents from various isomers.

\section{Acknowledgments}

The authors thank Christen Buseman for preparation of the Arabidopsis lipid extract. Research at the Mass Spectrometry Resource of Washington University was supported by U.S. Public Health Service grants P41-RR-00954, R37-DK-34388, P60-DK20579, P01-HL-57278, and P30-DK56341. The Kansas Lipidomics Research Center's research was supported by grants from NSF (MCB 0455318, DBI 0521587, and Kansas EPSCoR award, EPS0236913), with support from the State of Kansas through Kansas Technology Enterprise Corporation and Kansas State University, as well as from U.S. Public Health Service grant P20 RR016475 from the INBRE program of the National Center for Research Resources.

\section{References}

1. Sakurai, I.; Hagio, M.; Gombos, Z.; Tyystjarvi, T.; Paakkarinen, V.; Aro, E. M.; Wada, H. Requirement of Phosphatidylglycerol for Maintenance of Photosynthetic Machinery. Plant Physiol. 2003, 133, 1376-1384.

2. Sato, N. Roles of the Acidic Lipids Sulfoquinovosyl Diacylglycerol and Phosphatidylglycerol in Photosynthesis: Their Specificity and Evolution. J. Plant Res. 2004, 117, 495-505.

3. Frentzen, M. Phosphatidylglycerol and Sulfoquinovosyldiacylglycerol: Anionic Membrane Lipids and Phosphate Regulation. Curr. Opin. Plant Biol. 2004, 7, 270-276.

4. Joyard, J.; Maréchal, E.; Miège, C.; Block, M. A.; Dorne, A.; Douce, R. Structure, distribution, and biosynthesis of glycerolipids from higher plant chloroplasts. In Lipids in Photosynthesis: Structure, Function, and Genetics; Siegenthaler, P. A.; Murata, N., Eds.; Kluwer Academic Publishers: Dordrecht, The Netherlands, 1998; pp 21-52.

5. Hagio, M.; Gombos, Z.; Várkonyi, Z.; Masamoto, K.; Sato, N.; Tsuzuki, M.; Wada, H. Direct Evidence for Requirement of Phosphatidylglycerol in Photosystem II of Photosynthesis. Plant Physiol. 2000, 124, 795-804.

6. Pineau, B.; Girard-Bascou, J.; Eberhard, S.; Choquet, Y.; Tremolieres, A.; Gerard-Hirne, C.; Bennardo-Connan, A.; Decottignies, P.; Gillet, S.; Wollman, F. A. A Single Mutation That Causes Phosphatidylglycerol Deficiency Impairs Synthesis of Photosystem II Cores in Chlamydomonas reinhardtii. Eur. J. Biochem. 2004, 271, 329-338. 
7. Haverkate, F.; de Gier, J; van Deenen, L. L. The Occurrence of 83 -TransHexadecenoic Acid in Phosphatidyl Glycerol from Spinach Leaves. Experientia 1964, 20, 511-512.

8. Dubacq, J. P.; Tremolires, A. Occurrence and Function of Phosphatidylglycerol Containing $\Delta^{3}$-Trans-Hexadecenoic Acid in Photosynthetic Lamellae. Physiol. Veg. 1983, 21, 293-312.

9. Selstam, E. Development of Thylakoid membranes with respect to lipids. In Advances in Photosynthesis, Vol. VI; Lipids in Photosynthesis: Structure, Function, and Genetics; Siegenthaler, P.-A.; Murata, N., Eds.; Kluwer Academic Publishers: Dordrecht, The Netherlands, 1998; pp 209-224.

10. Browse, J.; Warwick, N.; Somerville, C. R.; Slack, C. R. Fluxes Through the Prokaryotic and Eukaryotic Pathways of Lipid Synthesis in the "16:3" Plant Arabidopsis thaliana. Biochem. J. 1986, 235, 25-31.

11. Roughan, P. G. Phosphatidyl Choline: Donor of 18-Carbon Unsaturated Fatty Acids for Glycerolipid Biosynthesis. Lipids 1975, 10, 609-614.

12. Mackender, R. O.; Leech, R. M. The Galactolipid, Phospholipid, and Fatty Acid Composition of the Chloroplast Envelope Membranes of Vicia faba L. Plant Physiol. 1974, 53, 496-502.

13. Ohnishi, M.; Thompson, G. A., Jr. Biosynthesis of the Unique Trans- $\delta 3-$ Hexadecenoic Acid Component of Chloroplast Phosphatidylglycerol: Evidence Concerning Its Site and Mechanism of Formation. Arch. Biochem. Biophys. 1991, 288, 591-599.

14. Beisson, F.; Koo, A. J. K.; Ruuska, S.; Schwender, J.; Pollard, M.; Thelen, J.; Paddock, T.; Salas, J.; Savage, L.; Milcamps, A.; Mhaske, V. B.; Cho, Y.; Ohlrogge, J. B. Arabidopsis thaliana Genes Involved in Acyl Lipid Metabolism. A 2003 Census of the Candidates, a Study of the Distribution of Expressed Sequence Tags in Organs, and a Web-Based Database. Plant Physiol. 2003, 132, 681-697.

15. Dubertret, G.; Mirshahi, A.; Mirshahi, M.; Gerard-Hirne, C.; Tremolieres, A. Evidence from in Vivo Manipulations of Lipid Composition in Mutants that the 83-Trans-Hexadecenoic Acid-Containing Phosphatidylglycerol is Involved in the Biogenesis of the Light-Harvesting Chlorophyll A/B-Protein Complex of Chlamydomonas reinhardtii. Eur. J. Biochem. 1994, 226, 473-482.

16. Krupa, Z. The Action of Lipases on Chloroplast Membranes. III. The Effect of Lipid Hydrolysis on Chlorophyll-Protein Complexes in Thylakoid Membranes. Photosynth. Res. 1984, 5, 177-184.

17. Chapman, D. J.; De-Felice, J.; Barber, J. Characteristics of Chloroplast Thylakoid Lipid Composition Associated with Resistance to Triazine Herbicides. Planta 1985, 166, 280-285.

18. Xu, Y.; Siegenthaler, P.-A. Low Temperature Treatments Induce an Increase in the Relative Content of Both Linolenic and $\Delta 3$-Trans-
Hexadecenoic Acids in Thylakoid Membrane Phosphatidylglycerol of Squash Cotyledons. Plant Cell Physiol. 1997, 38, 611-618.

19. Lamberto, M.; Ackman, R. G. Confirmation by Gas Chromatography/ Mass Spectrometry of Two Unusual Trans-3-Monoethylenic Fatty Acids from the Nova Scotian Seaweeds Palmaria palmata and Chondrus crispus. Lipids 1994, 29, 441-444.

20. Lamberto, M. Ackman, R. G. Positional Isomerization of Trans-3Hexadecenoic Acid Employing 2-Amino-2-Methyl-Propanol as a Derivatizing Agent for Ethylenic Bond Location by Gas Chromatography/ Mass Spectrometry. Anal. Biochem. 1995, 230, 224-228.

21. Welti, R.; Wang, X.; Williams, T. D. Electrospray Ionization Tandem Mass Spectrometry Scan Modes for Plant Chloroplast Lipids. Anal. Biochem. 2003, 314, 149-152.

22. Hsu, F. F.; Turk, J. Studies on Phosphatidylglycerol with Triple Quadrupole Tandem Mass Spectrometry with Electrospray Ionization: Fragmentation Processes and Structural Characterization. J. Am. Soc. Mass Spectrom. 2001, 12, 1036-1043.

23. Xu, Y.; Siegenthaler, P. A. Phosphatidylglycerol Molecular Species of Photosynthetic Membranes Analyzed by High-Performance Liquid Chromatography: Theoretical Considerations. Lipids 1996, 31, 223-229.

24. Christie, W. W. Lipid Analysis, 2nd ed.; Pergamon Press: Oxford, United Kingdom, 1982; pp 109-110.

25. Hsu, F. F.; Turk, J. Electrospray Ionization with Low-Energy Collisionally Activated Dissociation Tandem Mass Spectrometry of Complex Lipids: Structural Characterization and Mechanisms of Fragmentation. In Modern Methods for Lipid Analysis by Liquid Chromatography/Mass Spectrometry; Byrdwell, W. C., Ed.; AOCS Press: Champaign, IL. 2005; pp 61-178.

26. Hsu, F. F.; Turk, J. Charge-Driven Fragmentation Processes in Diacyl Glycerophosphatidic Acids upon Low-Energy Collisional Activation. A Mechanistic Proposal. J. Am. Soc. Mass Spectrom. 2000, 11, 797-803.

27. Hong, S.; Lu, Y.; Yanag, R.; Gotlinger, K. H.; Petasis, N. P.; Serhan, C. N. Resolvin D1, Protectin D1, and Related Docosahexaenoic Acid-Derived Products: Analysis Via Electrospray/Low Energy Tandem Mass Spectrometry Based on Spectra and Fragmentation Mechanisms. J. Am. Soc. Mass Spectrom. 2006, 18, 128-144.

28. Moe, M. K.; Anderssen, T.; Strøm, M. B.; Jensen, E. Total Structure Characterization of Unsaturated Acidic Phospholipids Provided by Vicinal Dihydroxylation of Fatty Acid Double Bonds and Negative Electrospray Ionization Mass Spectrometry. J. Am. Soc. Mass Spectrom. 2005, 16, 46-59.

29. Thomas, M. C.; Mitchell, T. W.; Blanksby, S. J. Ozonolysis of Phospholipid Double Bonds during Electrospray Ionization: A New Tool for Structure Determination. J. Am. Chem. Soc. 2006, 128, 58-59. 